\title{
A Human-Derived Reporter Gene for Noninvasive Imaging in Humans: Mitochondrial Thymidine Kinase Type 2
}

\author{
Vladimir Ponomarev ${ }^{1}$, Michael Doubrovin ${ }^{2}$, Aleksander Shavrin ${ }^{3}$, Inna Serganova ${ }^{2}$, Tatiana Beresten ${ }^{2}$, Ludmila Ageyeva ${ }^{2}$, \\ Changde $\mathrm{Cai}^{4}$, Julius Balatoni ${ }^{3}$, Mian Alauddin ${ }^{3}$, and Juri Gelovani ${ }^{3}$ \\ ${ }^{1}$ Department of Radiology, Memorial Sloan-Kettering Cancer Center, New York, New York; ${ }^{2}$ Department of Neurology, Memorial Sloan- \\ Kettering Cancer Center, New York, New York; ${ }^{3}$ Department of Experimental Diagnostic Imaging, M.D. Anderson Cancer Center, \\ University of Houston, Houston, Texas; and ${ }^{4}$ Radiochemistry/Cyclotron Core Facility, Memorial Sloan-Kettering Cancer Center, \\ New York, New York
}

A human-derived intrinsically nonimmunogenic reporter gene was tested for PET imaging of different molecular-genetic processes for potential clinical use. Methods: The human mitochondrial thymidine kinase type 2 (hTK2) reporter gene truncated at the $\mathrm{N}$ terminus ( $\Delta$ hTK2), alone or fused with green fluorescent protein (GFP), was used for preclinical evaluation in a mouse model. The levels of enzymatic activity of $\Delta h T K 2$ and $\Delta h T K 2$ GFP proteins were assessed using radiotracer accumulation and prodrug activation assays in vitro and in subcutaneous tumors grown from the corresponding cell lines in nude mice. Kinetic analyses of ${ }^{124} \mid-2^{\prime}-$ fluoro- 2 '-deoxy-1- $\beta$-D- $\beta$-arabinofuranosyl-5-iodouracil (FIAU), ${ }^{18} \mathrm{~F}$ 2 '-fluoro-2'-deoxy-1- $\beta$-D- $\beta$-arabinofuranosyl-5-ethyluracil (FEAU), or ${ }^{18} \mathrm{~F}-9-\left(4-{ }^{18} \mathrm{~F}-\right.$ fluoro-3-hydroxymethylbutyl)guanine (FHBG) uptake in tumors and biodistribution studies were performed. Results: $\Delta$ hTK2 was successfully expressed in the cytoplasm of transduced cells. A new anti-hTK2 monoclonal antibody 8G2 was developed. The levels of FIAU and FEAU accumulation in cells expressing $\Delta$ hTK2 and $\triangle \mathrm{hTK} 2$ GFP were at least 10-fold higher than in wildtype cells in vitro and about 6 times higher in vivo. We determined that FEAU is a more specific reporter substrate for $\triangle \mathrm{hTK} 2$ than FIAU, whereas FHBG is not phosphorylated by this enzyme. In addition, we showed that $\Delta \mathrm{hTK} 2$ transduced cells can be eliminated by treatment with D-arabinofuranosyl-cytosine. Conclusion: We have tested a human-derived reporter gene that is likely to be nonimmunogenic and potentially allows for long-term monitoring of different molecular-genetic processes by nuclear imaging techniques in humans. Using ${ }^{124} \mathrm{I}-\mathrm{FIAU},{ }^{18} \mathrm{~F}-\mathrm{FIAU}$, or ${ }^{18} \mathrm{~F}-\mathrm{FEAU}$, it should be possible to image $\triangle \mathrm{hTK} 2$ reporter gene expression with PET in preclinical and clinical studies.

Key Words: molecular imaging; human mitochondrial thymidine kinase; FEAU; FIAU; PET

J Nucl Med 2007; 48:819-826

DOI: 10.2967/jnumed.106.036962

Received Oct. 5, 2006; revision accepted Jan. 20, 2007.

For correspondence or reprints contact: Juri Gelovani, MD, PhD, Department of Experimental Diagnostic Imaging, M.D. Anderson Cancer Center, University of Houston, Unit 057, 1515 Holcombe Blvd., Houston, TX 77030-4095.

E-mail: jgelovani@mdanderson.org

COPYRIGHT @ 2007 by the Society of Nuclear Medicine, Inc.
$\mathbf{R}$ ecent advances in noninvasive molecular imaging have provided new research tools for monitoring the expression of different genes and activities of various signal transduction pathways. Reporter systems have been developed for tracking transgene expression in vitro as well as in vivo, and in transgenic animals. Stable genetic cell labeling with various reporter genes has been used to circumvent the temporal limitations of in vitro radiolabeling or magnetic labeling of cells. The paradigm for imaging with reporter genes involves administration of a probe that is selectively bound or metabolized and is trapped by interaction with the gene product in the reporter gene transduced cell. The level of probe accumulation is proportional to the level of reporter gene product expressed (1).

Wild-type herpes simplex virus type 1 thymidine kinase (HSV1-tk) and mutant HSV1-sr39tk are the most widely used reporter genes for PET imaging, and the 2 most widely used radiolabeled reporter probes are ${ }^{124} \mathrm{I}-2^{\prime}$-fluoro- $2^{\prime}$-deoxy$1-\beta$-D- $\beta$-arabinofuranosyl-5-iodouracil (FIAU) (with its derivative, ${ }^{18} \mathrm{~F}$-2' -fluoro- $2{ }^{\prime}$-deoxy-1- $\beta$-D- $\beta$-arabinofuranosyl-5ethyluracil [FEAU]) and ${ }^{18} \mathrm{~F}-9-\left(4-{ }^{18} \mathrm{~F}-\right.$ fluoro-3-hydroxymethylbutyl)guanine (FHBG) (2,3). The initial clinical imaging studies reported by Jacobs et al. (4) showed successful ${ }^{124}$ I-FIAU PET imaging of liposome-mediated direct intratumoral HSV1-tk gene delivery and expression in glioblastoma patients (4). Yaghoubi et al. reported on the human pharmacokinetics of ${ }^{18}$ F-FHBG PET in healthy volunteers (5). A recent publication by Peñuelas et al. demonstrated that ${ }^{18} \mathrm{~F}-\mathrm{FHBG}$ PET can monitor HSV1-tk gene expression after intratumoral injection of adenovirus in hepatocellular carcinoma patients (6).

The major limitation for translation of virus- and bacteriumderived reporter gene imaging into clinical practice is the immunogenicity of these non-human-derived reporter proteins. This limitation is especially important when repetitive administration of a reporter gene or long-term monitoring of transgene expression is required, because of the potential for compromise by an immune reaction against this foreign 
protein. Several human-derived reporter genes for nuclear imaging have been proposed to circumvent this limitation, including dopamine receptor type 2 (7), somatostatin receptor (8), sodium iodide symporter (9), and norepinephrine transporter (10), as well as transferrin receptor (11) and ferritin (12) for MRI. However, receptor-ligand or transporterbased approaches are hindered by a relatively low sensitivity and narrow dynamic range caused by the intrinsic saturability of receptors even at radiotracer concentrations. High levels of reporter receptor expression on the cell membrane cannot be achieved because of competition for space on the cell membrane from other receptor types, which are required for cell viability (7). Furthermore, the level of binding of imaging agents to reporter receptors is significantly influenced by levels of endogenous natural ligands, which compete for binding and determine the receptor availability or occupancy (13). An example of a transporter-based reporter gene limitation is sodium iodide symporter, which has a short duration of imageable signal because organification of the radiolabeled substrate (radioiodine) is absent (9). Ultimately, reporter gene expression should not perturb cellular homeostasis (14).

Therefore, we aimed to develop a different human-derived reporter gene encoding for a nonimmunogenic endogenous enzyme that would be suitable for molecular-genetic imaging with radionuclide imaging modalities. We used the following selection criteria: the enzyme could be expressed transiently or at low levels, be metabolically poorly accessible to a substrate without a specifically coexpressed transporter, or be expressed in only a small amount of anatomically well-defined, specific tissue.

In this paper, we report on one such suitable human-derived reporter gene, human mitochondrial thymidine kinase type 2 (hTK2). Two of the 4 human deoxyribonucleoside kinases, deoxyguanosine kinase and hTK2, are expressed in mitochondria (15). hTK2 phosphorylates deoxythymidine, deoxycytidine, and deoxyuridine, as well as several antiviral and anticancer nucleoside analogs (16). The efficient phosphorylation of FIAU and other nucleoside analogs by hTK2 has also been reported as the cause of mitochondrial toxicity (16). Previously, we reported very low (not able to be imaged) levels of FIAU accumulation in tumor cells that do not express HSV1-tk and have low proliferative activity (2). The major reason why FIAU is not efficiently entrapped by hTK2-mediated phosphorylation in naïve tumor cells is that the hTK2 is poorly accessible to FIAU. In mitochondria, the deoxyribonucleotide pool is separated from the cytosolic pool because the mitochondrial inner membrane is impermeable to charged molecules. In contrast, human thymidine kinase type 1 (hTK1) is expressed in the cytoplasm of rapidly proliferating cells and can be imaged noninvasively with PET using ${ }^{11} \mathrm{C}$-thymidine or other radiolabeled nucleoside analogs: ${ }^{18} \mathrm{~F}$-fluorothymidine (17), 2'-fluoro-5- ${ }^{11} \mathrm{C}$-methyl-1-beta-D-arabinofuranosyluracil $\left({ }^{11} \mathrm{C}-\mathrm{FMAU}\right)(18)$ or ${ }^{18} \mathrm{~F}-\mathrm{FMAU}(19)$, and ${ }^{124} \mathrm{I}$-iodeoxyuridine $(20)$.
In this paper, we describe a human-derived reporter gene, mitochondrial thymidine kinase type 2, that has been truncated in the $\mathrm{N}$ terminus to eliminate the nuclear localization signal $(\Delta \mathrm{hTK} 2)$ and, as a result, is expressed throughout the cell cytoplasm. Noninvasive imaging of retrovirus-mediated expression of $\Delta \mathrm{hTK} 2$ in tumor xenografts in vivo was achieved using ${ }^{124}$ I-FIAU and ${ }^{18}$ F-FEAU PET.

\section{MATERIALS AND METHODS}

\section{Human Thymidine Kinase/Green Fluorescent Protein (GFP) Retroviral Vectors}

The schematic structures of retroviral vectors used in this study are presented in Figure 1. hTK2 complementary DNA (cDNA) truncated at ${ }^{18} \mathrm{Ser}(\Delta \mathrm{hTK} 2)$ and cloned into pET-14b vector with the N-terminal fusion 6xHis-tag (Gene Bank Y10498) was kindly provided by Liya Wang (Swedish University of Agricultural Sciences). The $\triangle \mathrm{hTK} 2 \mathrm{cDNA}$ fragment lacking stop codon was amplified using 2 primers (5'-CGTACGTCACGTGCCGGCCATCGATCATATGGCATCAGTGATCTGTGTCG-3' and 5'-ACGTACGTGGATCCTTACACGTGGGCCGGCCCTGGGCAATGCTTCCG-3'), digested with PmlI and HpaI, and subcloned into corresponding restriction sites of the retroviral vector SFG-wtHSV1-tk/GFP described by us previously (21), replacing the HSV1-tk cDNA. The resulting vector was termed SFG- $\Delta \mathrm{hTK} 2$ GFP (Fig. 1A). With the same primer pair, the $\triangle \mathrm{hTK} 2 \mathrm{cDNA}$ fragment including a stop codon was amplified, digested with PmlI and BamHI, and placed into the retroviral vector SFG-HSV1-tk internal ribosomal entry site (IRES) GFP, replacing the HSV1-tk cDNA. The resulting vector was termed SFG- $\Delta$ hTK2-IRES GFP (Fig. 1A).

\section{Transduction of Tumor Cells}

The U87 human glioma cell line was obtained from American Type Culture Collection and grown as cell monolayers in minimal essential medium supplemented with $10 \%$ fetal calf serum. The U87 cells were transduced in vitro with retroviral vectors by exposing U87 cell monolayers to a filtered $(0.45-\mu \mathrm{m})$ culture medium obtained from the vector producer cells for $8 \mathrm{~h}$ in the presence of polybrene $(8 \mu \mathrm{g} / \mathrm{mL})$, as previously described (21).

\section{Flow Cytometry and Fluorescent Microscopy}

Retroviraly transduced U87 cells were grown as bulk cultures for $48 \mathrm{~h}$ and subsequently sorted for positive GFP expression using fluorescence-activated cell sorting (FACS) (FACSVantage; Becton Dickinson); the 488-nm excitation beam and 510-nm emission filter were used. Subcellular localization of the $\Delta \mathrm{hTK} 2$ GFP in transduced tumor cells was visualized by fluorescence microscopy (Nikon) using similar excitation and emission parameters.

\section{Production and Purification of $\Delta \mathrm{hTK} 2$ Protein and $\Delta$ hTK2-Specific Monoclonal Antibody}

The $\Delta$ hTK2 cDNA with N-terminal fusion 6xHis-tag in the pET-14b plasmid (Gene Bank Y10498) was transformed into the BL-21p(LYS)ES strain of Escherichia coli (Novogen). Inoculated medium ( $800 \mathrm{~mL}$, with $100 \mu \mathrm{g} / \mathrm{mL}$ of carbenicillin) was incubated at $37^{\circ} \mathrm{C}$ and vigorously shaken until an optical density of 0.6 was reached. Expression was induced by adding isopropyl- $\beta$-thiogalactopyranoside (Sigma Chemical Co.) to a final concentration of $1 \mathrm{mM}$. Incubation was continued until an optical density of 1.2 was reached, and cells were harvested by centrifugation at $15,000 \mathrm{~g}$ 


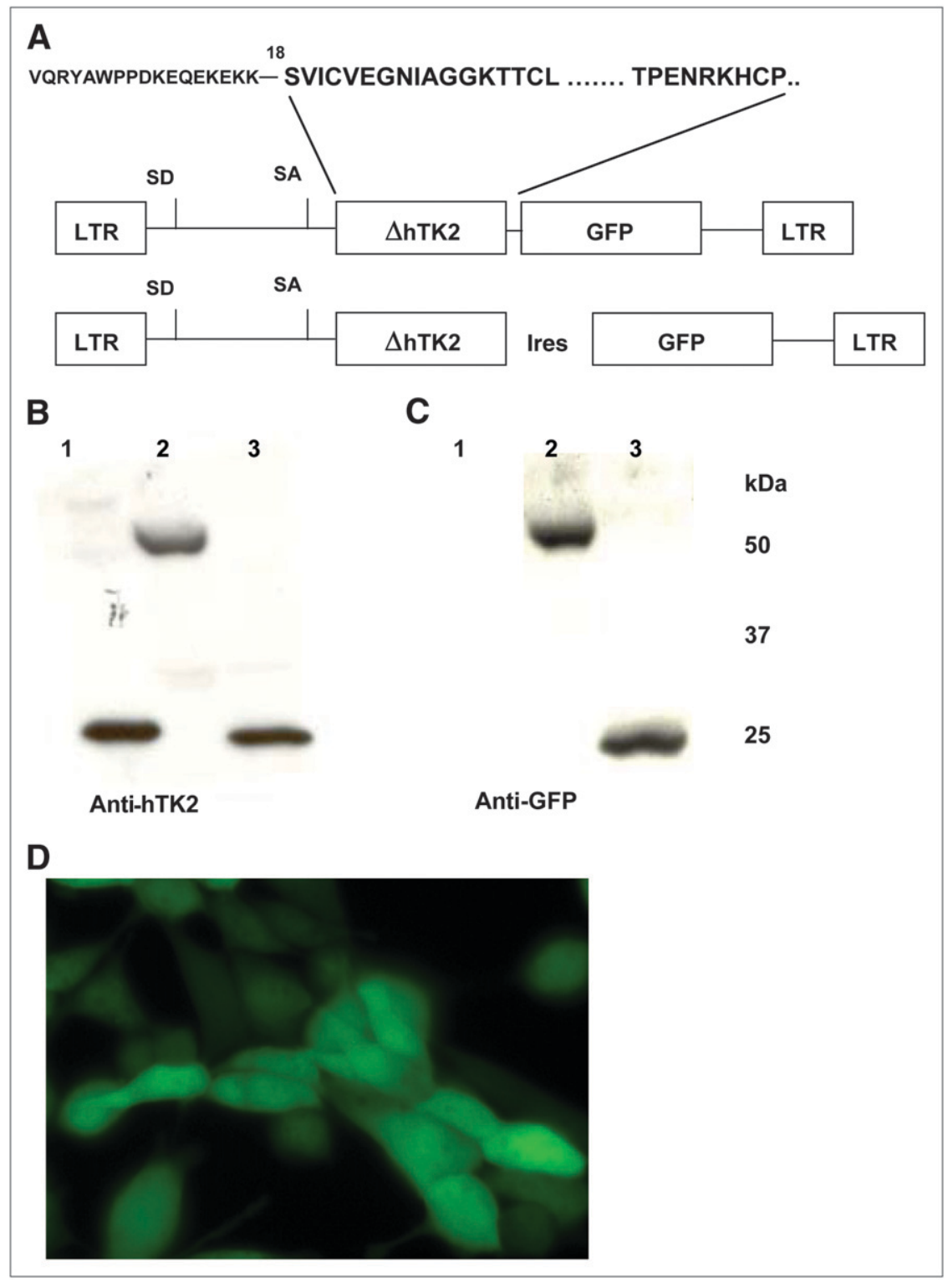

FIGURE 1. (A) Schematic representation of $\Delta h T K 2$-bearing retroviral vectors encoding $\triangle$ hTK2 GFP fusion gene and $\triangle \mathrm{hTK} 2$ and GFP genes linked by encephalomyocarditis virus IRES element. (B and C) Western blots of $\Delta h T K 2$-expressing cell lysates with anti-hTK2 (B) and anti-GFP (C) monoclonal antibodies. (D) Fluorescent microscopy of U87/DhTK2 GFP cells using GFP filter set. LTR = long-terminal repeat.

for $20 \mathrm{~min}$ at $+4^{\circ} \mathrm{C}$ (Sorvall $\mathrm{RC}-5 \mathrm{~B}$ ). The bacterial pellet was frozen at $-80^{\circ} \mathrm{C}$ and stored. Then, the bacterial pellet was thawed on ice and homogenized in $35 \mathrm{~mL}$ of lysis buffer $(100 \mathrm{mM}$ $\mathrm{NaH} 2 \mathrm{PO} 4,0.5 \mathrm{M} \mathrm{NaCl}, 8 \mathrm{M}$ Urea, $\mathrm{pH}$ 8.0) in a glass-glass homogenizer. Lysozyme (1 mg/mL, Sigma Chemical Co.) was added, and the suspension was incubated at $+4{ }^{\circ} \mathrm{C}$ for 30 min with shaking, followed by sonication $(6 \times 10 \mathrm{~s}, 80 \mathrm{~W}$, on ice.). Benzoate $(1 \mu \mathrm{L} / \mathrm{mL}$, Novagen) and Protease Inhibitor Cocktail III ( $2 \mu \mathrm{L} / \mathrm{mL}$, Novagen) were added, and the lysate was incubated at room temperature for $3 \mathrm{~h}$ and then centrifuged at 15,000 $\mathrm{g}$ for $30 \mathrm{~min}$ at $+4^{\circ} \mathrm{C}$. The supernatant was passed through a $0.45-\mu \mathrm{m}$ filter (Pall Corp.). $\Delta$ hTK2 protein was purified using fast protein liquid chromatography (BioLogic LP; Bio-Rad), and HiTrap affinity columns were loaded with $\mathrm{Ni}^{2+}$ (Amersham Pharmacia Biotech). The bacterial lysate was applied to a column with a flow rate of $1 \mathrm{~mL} / \mathrm{min}$ and then eluted with a lysis buffer under a $\mathrm{pH}$ gradient of 8.0 to 4.0. Multiple fractions were collected and analyzed by sodium dodecylsulfate (SDS)-polyacrylamide gel electrophoresis (PAGE) to obtain the pure $\Delta \mathrm{hTK} 2$ protein.
The anti- $\Delta \mathrm{hTK} 2$ monoclonal antibody clone $\Delta \mathrm{hHTK}-8 \mathrm{G} 2-$ AF11-1 was generated at the Monoclonal Antibody Facility of Memorial Sloan-Kettering Cancer Center. Briefly, BALB/c female mice were immunized 5 times intraperitoneally with $1-6 \mu \mathrm{g}$ of purified $\Delta \mathrm{hTK} 2$ protein in urea emulsified in $50 \mu \mathrm{L}$ of TiterMax (TiterMax USA, Inc.). After having been allowed to rest for more than $1 \mathrm{mo}$, the best responder was boosted with $9 \mu \mathrm{g}$ of purified $\Delta \mathrm{hTK} 2$ protein intraperitoneally $5 \mathrm{~d}$ before the splenocytes were fused with SP2/0-Ag14 (American Type Culture Collection) using polyethylene glycol-1500 (Roche). The fusion was plated $5 \mathrm{~h}$ later into 25- to 96-well plates and cultured for $7 \mathrm{~d}$ in Hybridoma-SFM (Invitrogen) supplemented with $15 \%$ fetal bovine serum, $1 \%$ hybridoma cloning factor (BioVeris), $10 \mathrm{mg} / \mathrm{mL}$ gentamycin (Invitrogen), and $1 \times$ hypoxanthine, aminopterin, thymidine (Sigma). The fusion was performed, and wells greater than $50 \%$ confluent were selected, expanded twice, and frozen over the next $2 \mathrm{wk}$. Screening involved an initial enzyme-linked immunosorbent assay using purified $\Delta$ hTK2 protein and whole-cell lysates from U87/DhTK2 GFP and U87/DhTK2-IRES GFP cells; thereafter, the enzyme-inked 
immunosorbent assay-positive hybridoma clones were tested by Western blot.

\section{Western Blot of $\Delta \mathrm{hTK} 2, \mathrm{GFP}$, and $\Delta \mathrm{hTK2}$ GFP}

The cells were washed with ice-cold phosphate-buffered saline and mechanically lysed in a buffer containing $10 \mathrm{mM}$ Trisz $\mathrm{HCl}$ ( $\mathrm{pH} 7.5$ ), $1 \mathrm{mM}$ dithiothreitol, $20 \%$ (v/v) glycerol, $1 \mathrm{mM}$ ethylenediaminetetraacetic acid, and protease inhibitor mixture (Sigma; $100 \mathrm{~mL} / 100 \mathrm{~mL}$ buffer). The samples were centrifuged at $4^{\circ} \mathrm{C}$ for $5 \mathrm{~min}$, and the supernatant was mixed with SDS sample buffer 1:2 and boiled for $5 \mathrm{~min}$. A $10-\mathrm{mL}$ sample was subjected to SDS-PAGE $(10 \%)$ and transferred to Immobilon polyvinylidene difluoride membrane (Millipore). GFP and $\Delta$ hTk2 GFP were assessed using anti-GFP antibody (catalog number 8362; Clontech) at a 1:500 dilution. $\Delta \mathrm{hTK} 2$ recombinant protein, $\Delta \mathrm{hTK} 2$, and $\Delta \mathrm{hTK} 2$ GFP from U87 cell lysates were assayed using the murine serum described above (dilution, 1:500) and purified monoclonal antibodies (dilution, 1:5,000). Immunochemical detection of these proteins was performed using chemiluminescence (ECL kit; GE Healthcare). The protein concentration in samples was assayed using a protein assay kit (Bio-Rad).

\section{FIAU, FEAU, and Penciclovir Accumulation Assay}

The radiotracer accumulation assays were performed as previously described (1). The cells were seeded in $150 \times 25 \mathrm{~mm}$ tissue culture plates (Nunc) at a concentration of $1 \times 10^{6}$ cells per plate and grown until 50\%-60\% confluent. The incubation medium was replaced with $14 \mathrm{~mL}$ of medium containing [2- $\left.{ }^{14} \mathrm{C}\right]$ FIAU, 370 $\mathrm{Bq} / \mathrm{mL}(2,072 \mathrm{MBq} / \mathrm{mmol})$, and $\left[\mathrm{met}^{-}{ }^{3} \mathrm{H}\right]$ thymidine, $7,400 \mathrm{~Bq} / \mathrm{mL}$ $(2,200 \mathrm{GBq} / \mathrm{mmol})$, or $\left[2-{ }^{14} \mathrm{C}\right]$ thymidine, $370 \mathrm{~Bq} / \mathrm{mL} \quad(2,072$ $\mathrm{MBq} / \mathrm{mmol}$ ), and $\left[\mathrm{met}^{3}{ }^{3} \mathrm{H}\right] \mathrm{FEAU}$ or $\left[\mathrm{met}^{3} \mathrm{H}\right]$ penciclovir, 7,400 $\mathrm{Bq} / \mathrm{mL}$ (2,200 GBq/mmol) (Moravek Biochemicals). The radiochemical purity of each compound was checked in our laboratory using high-pressure liquid chromatography and found to be more than $98 \%$. The cells were harvested by scraping after various periods of incubation (10, 30, 60, 90, and $120 \mathrm{~min}$ ) and were centrifuged, and the cell pellets were weighed and assayed for radioactivity concentration on a TriCarb $1600 \beta$-spectrometer (Packard) using standard ${ }^{3} \mathrm{H}$ and ${ }^{14} \mathrm{C}$ dual-channel counting techniques. The medium was also counted before and after incubation. The data were expressed as a harvested cell-to-medium concentration ratio (dpm/g of cells $) /(\mathrm{dpm} / \mathrm{mL}$ of medium). The rates of accumulation (Ki) for FIAU, FEAU, penciclovir, and thymidine were determined from the slope of the cell-to-medium ratios versus incubation time plots and have units of tracer clearance from the medium (milliliters of medium/min/g of cells). The ratio of $\mathrm{Ki}$ values (the FIAU-to-thymidine, FEAU-to-thymidine, and penciclovir-to-thymidine ratios) is a measure of $\Delta \mathrm{hTK} 2$ activity and correlates with independent measures of gene expression (1).

\section{Assessment of Drug Sensitivity of $\triangle \mathrm{hTK} 2 \mathrm{GFP}$ and $\Delta$ hTK2-IRES GFP Cells to Different Nucleoside Analogs}

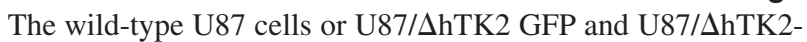
IRES GFP cells were seeded into 96-well plates (Nunc) at 2,000 cells per well and treated with various concentrations of different nucleoside analogs for $4 \mathrm{~d}$. Cell viability was assessed using a WST-1 assay (Roche) according to the manufacturer's protocol with a microplate spectrophotometer (Spectra Count; Packard BioScience Co.).

\section{Subcutaneous Tumors and Study Groups}

The experimental protocol involving animals was approved by the Institutional Animal Care and Use Committee of the Memorial Sloan-Kettering Cancer Center. The wild-type U87 cells and transduced U87 cells expressing $\triangle \mathrm{hTK} 2$ GFP were released from the culture plates by treatment with $0.5 \%$ trypsin in phosphate-buffered saline for 5-10 min, resuspended in the growth medium to neutralize the trypsin, centrifuged to obtain the cellular pellet, and then resuspended in minimal essential medium (without fetal calf serum) at a concentration of $10^{6}$ viable cells in $100 \mu \mathrm{L}$. Tumor cells $\left(10^{6}\right.$ cells in $\left.100 \mu \mathrm{L}\right)$ were injected subcutaneously into 18 nu/nu mice (Taconic) weighing 20-25 g. In each mouse, 2 subcutaneous tumors - the wild-type U87 tumor and the $\Delta$ hTK2 GFP tumor-were produced by injection of $10^{6}$ cells subcutaneously into the dorsal aspects of the left and right shoulders, respectively.

\section{PET with ${ }^{124}$ I-FIAU, ${ }^{18}$ F-FEAU, and ${ }^{18}$ F-FHBG}

No-carrier-added ${ }^{18} \mathrm{~F}$-FHBG, ${ }^{124} \mathrm{I}$-FIAU, and ${ }^{18} \mathrm{~F}-\mathrm{FEAU}$ were prepared as previously described (22-24). The mice were anesthetized (a 2:98 isoflurane:oxygen gas mixture). The mice were pretreated with $1 \mathrm{~mL}$ of $0.9 \% \mathrm{NaI}$ solution intraperitoneally $24 \mathrm{~h}$ before radiotracer injection when required to block thyroid accumulation of small amounts of radiolysed ${ }^{124}$ I-iodide. In the first group of animals $(n=6)$, PET was performed $2 \mathrm{~h}$ after intravenous administration of $7.4 \mathrm{MBq}$ of ${ }^{18} \mathrm{~F}$-FEAU per animal on the first day. On the next day ( $24 \mathrm{~h}$ later), the same animal was injected intravenously with $7.4 \mathrm{MBq}$ of ${ }^{18} \mathrm{~F}-\mathrm{FHBG}$ and imaged at $2 \mathrm{~h}$. On the third day, the same animal was injected intravenously with $7.4 \mathrm{MBq}$ of ${ }^{124}$ I-FIAU, and PET images were acquired $24 \mathrm{~h}$ afterward, followed by tissue sampling. PET was performed using a dedicated small-animal PET scanner (microPET; Concorde). Images were reconstructed using an ordered-subsets expectation maximization iterative reconstruction algorithm. To estimate the tumor dosimetry of ${ }^{124}$ I-FIAU and to confirm the PET radioactivity measurements, we sampled, weighed, and assayed the individual tumors, muscle, venous blood, and liver for ${ }^{124} \mathrm{I}$ radioactivity using a $5500 \gamma$-spectrometer (Packard).

Two additional groups of animals $(n=6$ each) were injected with $7.4 \mathrm{MBq}$ of ${ }^{18} \mathrm{~F}$-FEAU or $7.4 \mathrm{MBq}$ of ${ }^{18} \mathrm{~F}$-FHBG per animal, and PET images were acquired $2 \mathrm{~h}$ after tracer administration; thereafter, the animals were sacrificed, and individual tumors, muscle, and venous blood were sampled, weighed, and assayed for ${ }^{18} \mathrm{~F}$ radioactivity.

\section{Statistics}

Descriptive statistics of group data were obtained using univariate analysis. Group data were compared using ANOVA analysis, regression analysis, and the Student $t$ test; a $P$ value of less than 0.05 was considered significant. Statistical analysis of data was performed using StatView 4.57 (Abacus Concepts) and KaleidaGraph 3.5 (Synergy).

\section{RESULTS}

\section{Expression and Assessment of $\Delta \mathrm{hTK} 2$ Protein In Vitro}

Western blot analysis detected highly immunoreactive bands of purified proteins at approximately $29 \mathrm{kDa}$ for $\Delta \mathrm{hTK} 2$ protein, approximately $55 \mathrm{kDa}$ for $\Delta \mathrm{hTK} 2 \mathrm{GFP}$, and approximately $27 \mathrm{kDa}$ for $\Delta \mathrm{hTK} 2$ fusion GFP (Fig. 1B). The lower sensitivity threshold for the $\Delta$ hHTK-8G2AF11-1 monoclonal antibody was determined to be a 
1:50,000 dilution (data not shown). Western blot with antiGFP antibodies showed a GFP-immunoreactive band for the $\Delta \mathrm{hTK} 2$ fusion GFP at approximately $55 \mathrm{kDa}$ and for the IRES-mediated coexpressed GFP at approximately $27 \mathrm{kDa}$, as predicted (Fig. 1C).

Fluorescent microscopic analysis of U87 tumor cells transduced with SFG- $\Delta \mathrm{hTK} 2 \mathrm{GFP}$ retroviral vector demonstrated a pancellular distribution of $\Delta \mathrm{hTK} 2$ GFP (Fig. 1D).

The levels of enzymatic activity of $\Delta \mathrm{hTK} 2$ and $\Delta \mathrm{hTK} 2$ GFP were assessed using an FIAU accumulation assay in 12 different populations of transduced U87 cells with 6 significantly different levels of expression of $\Delta \mathrm{hTK} 2$ and $\Delta \mathrm{hTK} 2$ GFP. These populations of cells with different levels of fluorescence were obtained using FACS, expanded in vitro, and reanalyzed by FACS for the levels of fluorescence of GFP and $\triangle \mathrm{hTK} 2 \mathrm{GFP}$.

The slopes of the relationship between GFP fluorescence and the FIAU-to-thymidine accumulation ratio (enzymatic activity of the $\Delta \mathrm{hTK} 2$ subunit) reflects a constant relationship between the levels of expression of these reporter proteins in different transduced tumor cell populations. The magnitude of the FIAU-to-thymidine accumulation ratio (the $y$-intercept of the slope in Fig. 2A) in various populations of tumor cells expressing $\Delta \mathrm{hTK} 2$ protein was about 2 -fold higher than that measured in populations of cells expressing $\triangle \mathrm{hTK} 2$ GFP when normalized by the GFP expression levels (GFP fluorescence) in corresponding populations. Overall, the levels of FIAU accumulation in cells expressing $\Delta \mathrm{hTK} 2$ and $\Delta \mathrm{hTK} 2$ GFP were about 10 -fold higher than in wild-type cells.

The levels of enzymatic activity of $\Delta \mathrm{hTK} 2$ GFP were assessed using FIAU, FEAU, and penciclovir accumulation assays. FIAU and FEAU were efficiently phosphorylated by $\Delta$ hTK2 GFP enzyme. In contrast, no penciclovir phosphorylation was observed for $\Delta \mathrm{hTK} 2 \mathrm{GFP}$ enzyme (Fig. 2B). In wild-type U87 cells, background levels of FIAU, FEAU, and penciclovir accumulation were detected. The specificity of $\triangle \mathrm{hTK} 2$ GFP enzyme phosphorylation was assessed by calculating the ratio of radiotracer accumulation in $\Delta$ hTK2 GFP transduced cells to that in nontransduced cells, as represented in Figure 2C.

To explore the possibility of killing the $\Delta \mathrm{hTK} 2$ transduced cells using prodrug activation suicide therapy, the wild-type, $\Delta$ hTK2 GFP, and $\Delta$ hTK2-IRES GFP transduced U87 cells were tested for in vitro sensitivity to clinically relevant nucleoside analogs such as FIAU, D-arabinofuranosylcytosine (ara-C), FUdR, D-arabinofuranosyl-thymidine (ara-T), gemcitabine, and ganciclovir at different concentrations of these drugs. Among the tested drugs, ara-C showed an inhibitory concentration of $50 \%$ of as low as $0.04 \mu \mathrm{mol}$ for U87- $\Delta$ hTK2 GFP cells, compared with $0.260 \mu \mathrm{mol}$ for wild-type U87 cells (Fig. 3).

\section{In Vivo Imaging of $\triangle \mathrm{hTK} 2$ GFP Gene Expression with PET}

Small-animal PET imaging studies were performed on mice bearing subcutaneous tumor xenografts grown from $\Delta$ hTK2 GFP transduced U87 cell populations and wild-type U87 cells, which served as a negative control. Both transduced and wild-type tumors reached $5 \mathrm{~mm}$ in diameter, and no difference was observed between transduced and wildtype tumor growth. PET was performed on 3 consecutive days; therefore, there was no difference in the interval between tumor inoculation and PET with different tracers. A highly specific localization of ${ }^{124}$ I-FIAU- and ${ }^{18}$ F-FEAUderived radioactivity was revealed in tumor xenografts expressing the $\triangle \mathrm{hTK} 2$ GFP reporter gene (Figs. 4A and $4 \mathrm{C})$. The ${ }^{18} \mathrm{~F}-\mathrm{FHBG}$ accumulation in tumors expressing the $\Delta \mathrm{hTK} 2$ GFP reporter gene was low and comparable with the level of radioactivity in muscle (Fig. 4B). The levels
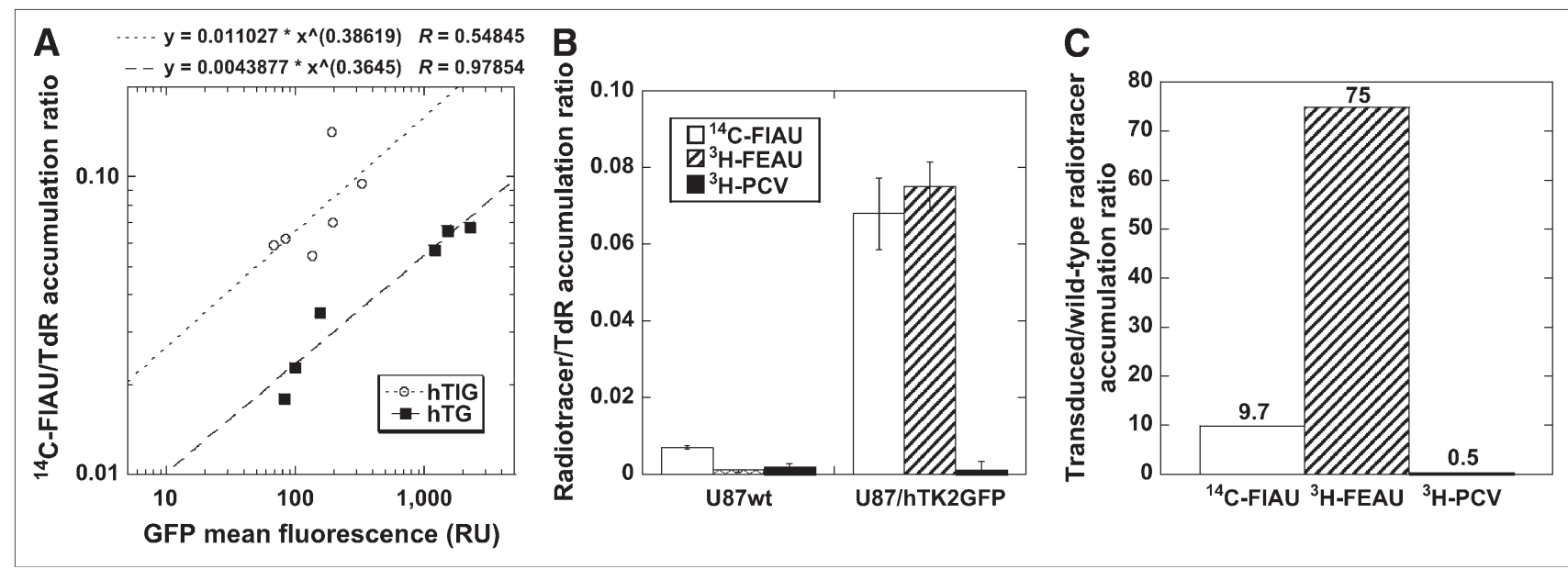

FIGURE 2. (A) Comparison of tracer accumulation and GFP fluorescence in populations expressing different levels of $\Delta$ hTK2 GFP (hTG) and $\Delta$ hTK2 coexpressed with GFP (hTIG) reporter genes. (B) Radiotracer uptake assay of FIAU, FEAU, and penciclovir in wild-type and $\triangle$ hTK2 GFP transduced U87 cells in vitro. (C). Radiotracer accumulation ratio in $\Delta$ hTK2 GFP transduced/wild-type U87 cells for FIAU, FEAU, and penciclovir in vitro. PCV = penciclovir; TdR = thymidine. 


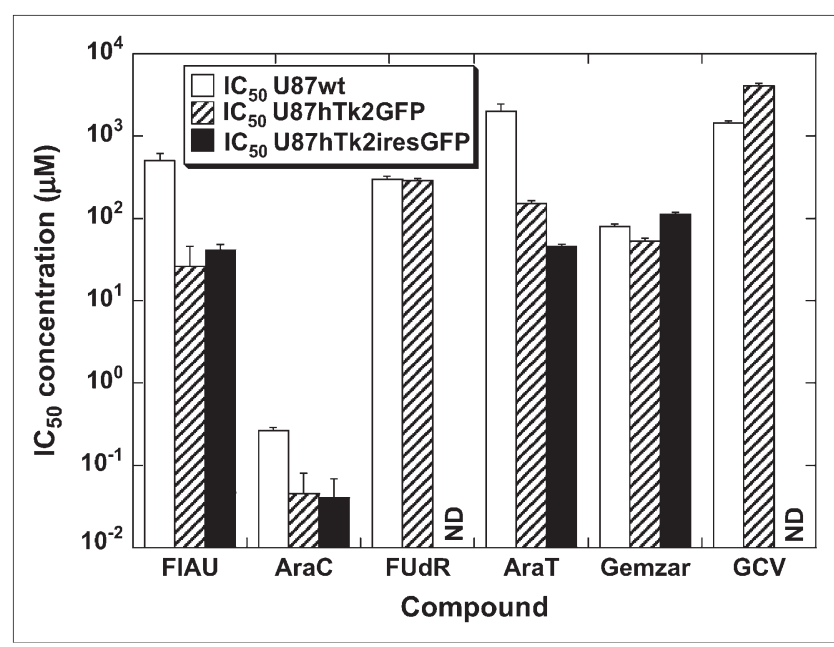

FIGURE 3. Assessment of drug sensitivity of $\Delta$ hTK2 GFP and $\triangle$ hTK2-IRES GFP transduced U87 cells to different nucleoside analogs in vitro. FUdR = fluorodeoxyuridine; GCV = ganciclovir; $I_{50}=$ inhibitory concentration of $50 \%$.

of ${ }^{124} \mathrm{I}$-FIAU, ${ }^{18} \mathrm{~F}-\mathrm{FEAU}$, and ${ }^{18} \mathrm{~F}$-FHBG radioactivity in control (nontransduced) U87 tumors were similar to muscle activity, which was very low (Fig. 4). Tissue sampling and biodistribution studies confirmed highly specific accumulations of ${ }^{124}$ I-FIAU- and ${ }^{18} \mathrm{~F}$-FEAU-derived radioactivity in U87- $\Delta$ hTK2 GFP tumors. The wild-type U87 tumors and other organs and tissues showed only low background levels of radioactivity (Fig. 5). Overall, the levels of ${ }^{124} \mathrm{I}-$ FIAU and ${ }^{18} \mathrm{~F}-\mathrm{FEAU}$ accumulation were about 6-fold higher in U87 tumors expressing $\Delta \mathrm{hTK} 2$ GFP reporter gene than in wild-type U87 tumors.

\section{DISCUSSION}

The effectiveness of cell- or vector-mediated gene therapy depends largely on the specificity and efficacy of gene delivery into target cells (and tissues) and the specificity, magnitude, and persistence of gene expression required for an optimum therapeutic effect. Recently, we and others demonstrated the feasibility of PET reporter gene imaging with HSV1-tk for monitoring the efficacy and durability of various cell therapies (25-29). In this paper, we describe a novel human-derived reporter gene, $\Delta \mathrm{hTK} 2$, that is suitable for PET of genetic and adoptive cell therapies with ${ }^{124} \mathrm{I}-$ FIAU or ${ }^{18} \mathrm{~F}-\mathrm{FEAU}$. We developed the $\Delta \mathrm{hTK} 2$ reporter gene to enable studies that require long-term monitoring of therapeutic gene coexpression in normal and neoplastic tissues, including adoptive immunotherapies, stem cell therapies, and other transplantation therapies. The $\Delta \mathrm{hTK} 2$ reporter gene was developed because the HSV1-tk reporter may induce immune-mediated rejection of gene-transfected cells and prevent long term PET-based monitoring of geneand cell-based therapies (30). In the study reported by Riddell et al., immune responses specific for the HSV1-tk protein developed in 5 of 6 patients who had received antiHIV cytotoxic HSV1-tk transduced T lymphocytes, and transduced $\mathrm{T}$ cells were eliminated (31). The rejection of genetically modified cells by these immunocompromised hosts suggests that strategies to render gene-modified cells less susceptible to host immune surveillance are required for successful gene therapy of immunocompetent hosts. Furthermore, administration of ganciclovir, which is routinely used for antiviral therapy in immunocompromised patients who have received transplanted bone marrow (stem cells), will eliminate the adoptively transferred HSV1-tk transduced stem cells or T cells. In contrast, hTK2 is intrinsically nonimmunogenic and can sensitize transduced cells to certain prodrugs (e.g., ara-C) for elimination of any undesired consequences of genetic and transplantation therapies (e.g., neoplastic transformation) while allowing patients receiving stem-cell or T-cell transplants to be treated with ganciclovir.

Several biochemical features of hTK2 make it an attractive PET reporter gene. In nonreplicating cells, where cytosolic deoxyribonucleotide synthesis is downregulated, mitochondrial DNA synthesis depends solely on the mitochondrial salvage pathway enzymes, the deoxyribonucleoside kinases, including hTK2, which is 1 of 4 human deoxyribonucleoside kinases that are expressed in mitochondria (15). The paradigm of applying $\Delta \mathrm{hTK} 2$ as a
FIGURE 4. Small-animal PET imaging of $\triangle$ hTK2 GFP expression with ${ }^{18}$ F-FEAU (A) and ${ }^{18} \mathrm{~F}-\mathrm{FHBG}(\mathrm{B})$ at $2 \mathrm{~h}$ and ${ }^{124} \mathrm{I}-\mathrm{FIAU}$ (C) at $24 \mathrm{~h}$ after radiotracer administration in same animal. U87/DhTK2 GFP tumor is in right shoulder; control U87 wild-type tumor is in left shoulder. \%ID/g = percentage injected dose per gram of tissue.
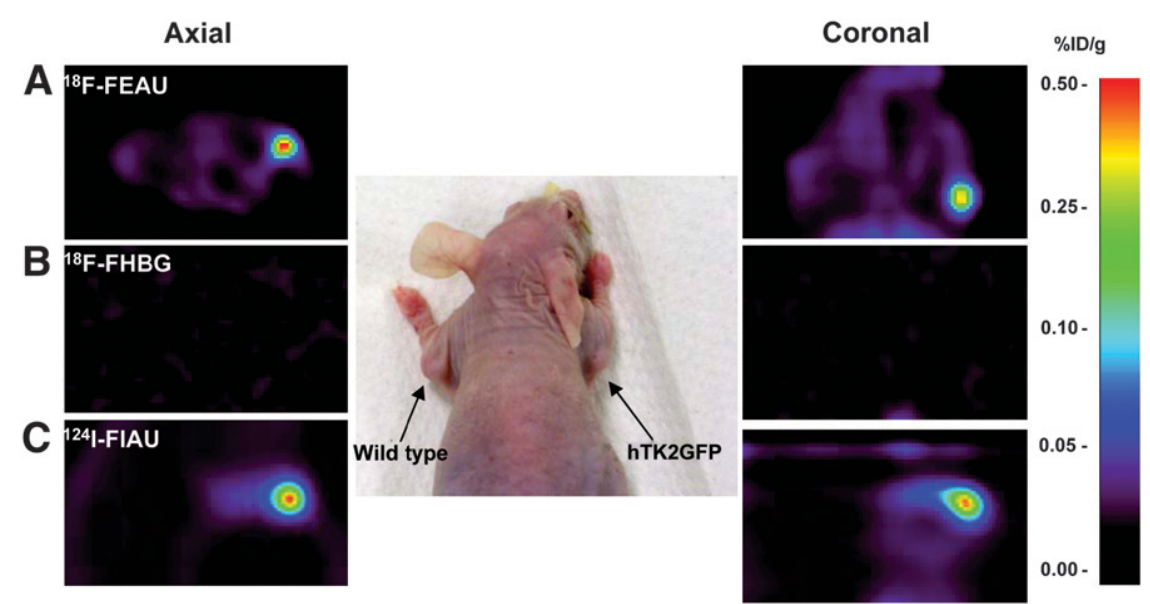


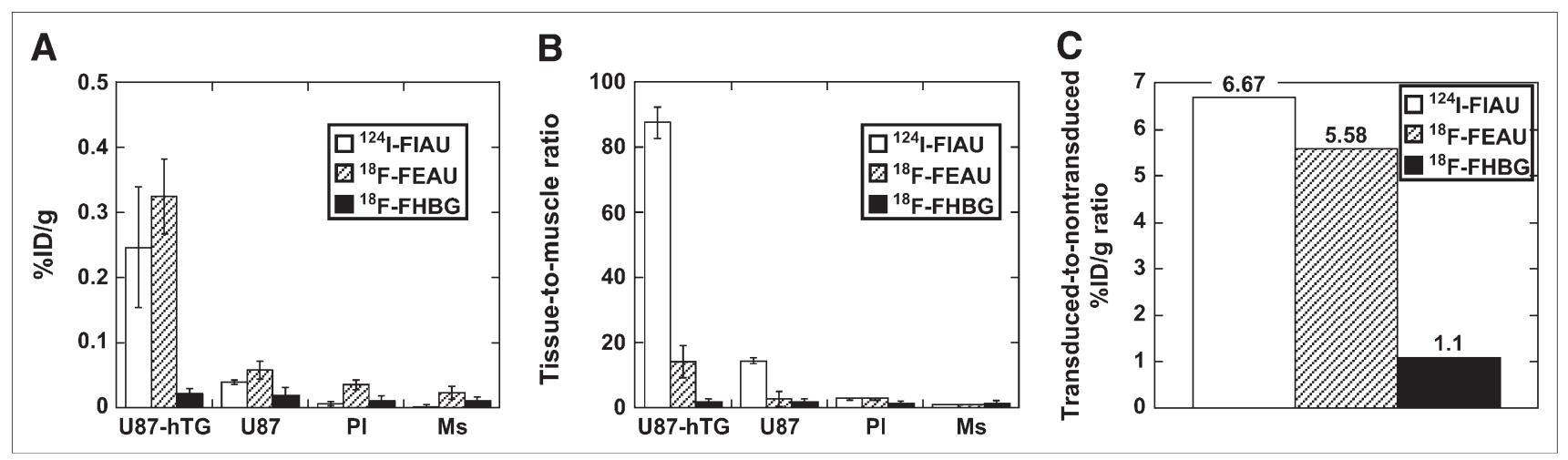

FIGURE 5. (A) In vivo radiotracer accumulation measurements for ${ }^{18} \mathrm{~F}-\mathrm{FEAU},{ }^{18} \mathrm{~F}-\mathrm{FHBG}$ at $2 \mathrm{~h}$, and ${ }^{124} \mathrm{I}-\mathrm{FIAU}$ at $24 \mathrm{~h}$ after radiotracer administration. (B and $\mathrm{C}$ ) Calculated tissue-to-muscle $(\mathrm{B})$ and transduced tumor-to-nontransduced tumor $(\mathrm{C})$ tracer accumulation ratios in vivo. $\% \mathrm{ID} / \mathrm{g}=$ percentage injected dose per gram of tissue; $\mathrm{PI}=$ plasma; $\mathrm{Ms}=$ muscle $(n=6 ; P<0.05)$.

clinically useful reporter gene is based on overexpression and retargeting of subcellular localization of $\Delta \mathrm{hTK} 2$ protein from mitochondria into the cell cytoplasm, where it will readily be metabolically accessible to radiolabeled nucleoside analogs ( ${ }^{124}$ I-FIAU and ${ }^{18}$ F-FEAU). Previously, we and others have observed that proper subcellular localization of a reporter protein plays an important role in the context of apparent enzymatic activity (21). In the current study, we tested a truncated version of hTK2 ( $\Delta$ hTK2) that lacks $18 \mathrm{~N}$-terminal amino acids responsible for mitochondrial localization of this protein (32). When overexpressed in fusion with GFP, $\triangle \mathrm{hTK} 2$ GFP exhibited a pancellular distribution in transduced cells, resulting in a significant increase in accumulation of the pyrimidine nucleoside analogs FIAU and FEAU in tumor cells expressing high levels of $\Delta \mathrm{hTK} 2$ or $\Delta \mathrm{hTK} 2$ GFP (Fig. 1). These data support our previous conclusions that cytoplasmic retargeting improves the bioavailability of reporter enzymes for corresponding reporter substrates (21). In rapidly proliferating cells, hTK1, being naturally expressed in the cell cytoplasm, phosphorylates thymidine and can phosphorylate FIAU (16), albeit to a significantly lesser degree. However, as we have demonstrated in this work (Figs. 2B and 2C), hTK1 cannot phosphorylate FEAU because of the steric clash between the larger-than-iodine 5-ethyl group of FEAU and amino acid Thr163 in the active site of hTK1 enzyme (33). We determined in vitro that FEAU is a more specific reporter substrate for $\triangle \mathrm{hTK} 2$ than for hTK1, as compared with FIAU (transduced-to-nontransduced ratios in vitro, 75 for FEAU and 9.7 for FIAU).

Although FIAU phosphorylation was approximately 4 times lower by $\Delta$ hTK2 than by the HSV1-tk enzyme expressed at similar levels (FIAU-to-thymidine ratios, 0.068 and 0.3 , respectively $(21)$ ), the accumulation of ${ }^{18} \mathrm{~F}$-FEAU and ${ }^{124}$ I-FIAU in $\triangle \mathrm{hTK} 2$ transduced tumors in vivo was more than sufficient for successful imaging with PET (transduced-to-nontransduced ratio, approximately 6). Others have reported similar or even lower values for different human-derived reporter genes suitable for nuclear imaging $(7-9,34)$. Although FIAU is usually labeled with ${ }^{124} \mathrm{I}$ for
PET studies (or with ${ }^{123} \mathrm{I}$ or ${ }^{131}$ I for $\gamma$-camera scintigraphy) and "late" imaging is usually performed, the feasibility of "early" FIAU imaging has been demonstrated by our group. Good-quality images can be obtained within the first 30 min to $2 \mathrm{~h}$ after radiolabeled FIAU administration (2). Our current data demonstrate that ${ }^{18} \mathrm{~F}-\mathrm{FEAU}$ can be used for imaging of $\Delta \mathrm{hTK} 2$ reporter gene expression at $2 \mathrm{~h}$ after tracer administration. Interestingly, although FEAU was shown to be superior to FIAU in vitro (transduced-tonontransduced ratios, 75 and 9.7, respectively; Fig. 2C), "late" imaging of ${ }^{124} \mathrm{FIAU}$ due to the longer ${ }^{124}$ I half-life $(\sim 4 \mathrm{~d})$ makes these tracers equally effective for PET in vivo (transduced-to-nontransduced ratios, 6.67 for FIAU at $24 \mathrm{~h}$ and 5.58 for FEAU at 2 h; Fig. 5B). Radiolabeling of FIAU and FEAU with ${ }^{11} \mathrm{C}$ is an alternative strategy and would provide additional positron-emitting probes for PET of $\Delta \mathrm{hTK} 2$ with high sensitivity and dynamic range. In addition, the very short half-life of ${ }^{11} \mathrm{C}(20 \mathrm{~min})$ should facilitate more frequent repetitive PET and would allow for sequential PET of $\Delta \mathrm{hTK} 2$ expression with ${ }^{11} \mathrm{C}$-FEAU, followed $4 \mathrm{~h}$ later by PET with a different tracer in the same subject.

\section{CONCLUSION}

We have developed, characterized, and validated in an animal tumor model in vivo a novel human-derived reporter gene, $\Delta \mathrm{hTK} 2$, that is likely to be nonimmunogenic for molecular genetic imaging with PET using specific radiolabeled nucleoside analogs (FIAU and FEAU) as reporter probes. $\Delta \mathrm{hTK} 2$ can be used as a reporter gene and as the pro-drug activation gene for therapy with routinely used anticancer nucleoside analogs, such as ara-C. We expect that $\Delta \mathrm{hTK} 2$ can rapidly be translated into clinical applications that require imaging for effective monitoring of various genetic and cellular therapies.

\section{ACKNOWLEDGMENTS}

This work was supported by several grants: NIH P50 CA86438-01, R01 CA102352, DOE DE-FG02-02ER63481, and DOE DE DE-FG02-86ER-60407. We thank Dr. Ronald 
Blasberg for helpful discussions and advice on preparation of the manuscript, Drs. William Bornmann and Ronald Finn for help with radiotracer production and advice on preparation of the manuscript, and Vilia Tourkova for excellent assistance with the in vitro studies.

\section{REFERENCES}

1. Tjuvajev J, Stockhammer G, Desai R, et al. Imaging the expression of transfected genes in vivo. Cancer Res. 1995;55:6126-6132.

2. Tjuvajev J, Doubrovin M, Akhurst $\mathrm{T}$, et al. Comparison of radiolabeled nucleoside probes (FIAU, FHBG, and FHPG) for PET imaging of HSV1-tk gene expression. J Nucl Med. 2002;43:1072-1083.

3. Min JJ, Iyer M, Gambhir SS. Comparison of $\left[{ }^{18} \mathrm{~F}\right] \mathrm{FHBG}$ and $\left[{ }^{14} \mathrm{C}\right] \mathrm{FIAU}$ for imaging of HSV1-tk reporter gene expression: adenoviral infection vs stable transfection. Eur J Nucl Med Mol Imaging. 2003;30:1547-1560.

4. Jacobs A, Voges J, Reszka R, et al. Positron-emission tomography of vectormediated gene expression in gene therapy for gliomas. Lancet. 2001;358:727-729.

5. Yaghoubi S, Barrio JR, Dahlbom M, et al. Human pharmacokinetic and dosimetry studies of $\left[{ }^{18} \mathrm{~F}\right] \mathrm{FHBG}$ : a reporter probe for imaging herpes simplex virus type1 thymidine kinase reporter gene expression. J Nucl Med. 2001;42:1225-1234.

6. Peñuelas I, Mazzolini G, Boan JF, et al. Positron emission tomography imaging of adenoviral-mediated transgene expression in liver cancer patients. Gastroenterology. 2005;128:1787-1795.

7. MacLaren D, Gambhir S, Satyamurthy N, et al. Repetitive, non-invasive imaging of the dopamine D2 receptor as a reporter gene in living animals. Gene Ther. 1999;6:785-791.

8. Rogers BE, Zinn KR, Buchsbaum DJ. Gene transfer strategies for improving radiolabeled peptide imaging and therapy. Q J Nucl Med. 2000;44:208-223.

9. Groot-Wassink T, Aboagye EO, Glaser M, Lemoine NR, Vassaux G. Adenovirus biodistribution and noninvasive imaging of gene expression in vivo by positron emission tomography using human sodium/iodide symporter as reporter gene. Hum Gene Ther. 2002;13:1723-1735.

10. Buursma A, Beerens A, de Vries E, et al. The human norepinephrine transporter in combination with ${ }^{11} \mathrm{C}$-m-hydroxyephedrine as a reporter gene/reporter probe for PET of gene therapy. J Nucl Med. 2005;46:2068-2075.

11. Moore AJ, Bhorade RM, Basilion JP, Weissleder R. Human transferrin receptor gene as a marker gene for MR imaging. Radiology. 2001;221:244-250.

12. Cohen B, Dafni H, Meir G, Harmelin A, Neeman M. Ferritin as an endogenous MRI reporter for noninvasive imaging of gene expression in C6 glioma tumors. Neoplasia. 2005;7:109-117.

13. Sasaki T, Ishiwata K, Murata T, Senda M. Demonstration of competition between endogenous dopamine and $\left[{ }^{11} \mathrm{C}\right]$ raclopride binding in in vitro brain slices using a dynamic autoradiography technique. Synapse. 2002;44:42-50.

14. Gol Choe J, Kim Y, Kim K, et al. Altered gene expression profiles by sodium/ iodide symporter gene transfection in a human anaplastic thyroid carcinoma cell line using a radioactive complementary DNA microarray. Nucl Med Commun. 2005;26:1155-1162.

15. Piskur J, Sandrini MP, Knecht W, Munch-Petersen B. Animal deoxyribonucleoside kinases: 'forward' and 'retrograde' evolution of their substrate specificity. FEBS Lett. 2004;560:3-6.

16. Wang J, Eriksson S. Phosphorylation of the anti-hepatitis B nucleoside analog 1-(2'-deoxy-2' -fluoro-1-beta-D-arabinofuranosyl)-5-iodouracil (FIAU) by human cytosolic and mitochondrial thymidine kinase and implications for cytotoxicity. Antimicrob Agents Chemother. 1996;40:1555-1557.

17. Shields A, Grierson J, Dohmen B, et al. Imaging proliferation in vivo with [F18]FLT and positron emission tomography. Nat Med. 1998;4:1334-1336.

18. Conti P, Alauddin MM, Fissekis JR, Schmall B, Watanabe KA. Synthesis of 2'fluoro-5-[ $\left.{ }^{11} \mathrm{C}\right]$-methyl-1-beta-D-arabinofuranosyluracil ( $\left.\left[{ }^{11} \mathrm{C}\right]-\mathrm{FMAU}\right)$ : a potential nucleoside analog for in vivo study of cellular proliferation with PET. Nucl Med Biol. 1995;22:783-789.

19. Mangner T, Klecker RW, Anderson L, Shields AF. Synthesis of $2^{\prime}$-deoxy-2'$\left[{ }^{18} \mathrm{~F}\right]$ fluoro-beta-D-arabinofuranosyl nucleosides, $\left[{ }^{18} \mathrm{~F}\right] \mathrm{FAU}, \quad\left[{ }^{18} \mathrm{~F}\right] \mathrm{FMAU}$, $\left[{ }^{18} \mathrm{~F}\right] \mathrm{FBAU}$ and $\left[{ }^{18} \mathrm{~F}\right] \mathrm{FIAU}$, as potential PET agents for imaging cellular proliferation: synthesis of $\left[{ }^{18} \mathrm{~F}\right]$ labelled FAU, FMAU, FBAU, FIAU. Nucl Med Biol. 2003;30:215-224.

20. Blasberg R, Roelcke U, Weinreich R, et al. Imaging brain tumor proliferative activity with $\left[{ }^{124} I\right]$ iododeoxyuridine. Cancer Res. 2000;60:624-635.

21. Ponomarev V, Doubrovin M, Serganova I, et al. Cytoplasmically retargeted HSV1-tk/GFP reporter gene mutants for optimization of non-invasive moleculargenetic imaging. Neoplasia. 2003;5:245-254.

22. Tjuvajev JG, Avril N, Oku T, et al. Imaging herpes virus thymidine kinase gene transfer and expression by positron emission tomography. Cancer Res. 1998;58: 4333-4341.

23. Alauddin M, Conti P. Synthesis and preliminary evaluation of 9- $\left(4-\left[{ }^{18} \mathrm{~F}\right]-\right.$ fluoro-3-hydroxymethylbutyl)guanine ([$\left.\left.{ }^{18} \mathrm{~F}\right] \mathrm{FHBG}\right)$ : a new potential imaging agent for viral infection and gene therapy using PET. Nucl Med Biol. 1998; 25:175-180.

24. Serganova I, Doubrovin M, Vider J, et al. Molecular imaging of temporal dynamics and spatial heterogeneity of hypoxia-inducible factor- 1 signal transduction activity in tumors in living mice. Cancer Res. 2004;64:6101-6108.

25. Dubey $\mathrm{P}, \mathrm{Su} \mathrm{H}$, Adonai $\mathrm{N}$, et al. Quantitative imaging of the $\mathrm{T}$ cell antitumor response by positron-emission tomography. Proc Natl Acad Sci U S A. 2003;100: $1232-1237$.

26. Koehne G, Doubrovin M, Doubrovina E, et al. Serial in vivo imaging of the targeted migration of human HSV-TK-transduced antigen-specific lymphocytes. Nat Biotechnol. 2003;21:405-413.

27. Wu J, Chen I, Sundaresan G, et al. Molecular imaging of cardiac cell transplantation in living animals using optical bioluminescence and positron emission tomography. Circulation. 2003;108:1302-1305.

28. Hung S, Deng W, Yang W, et al. Mesenchymal stem cell targeting of microscopic tumors and tumor stroma development monitored by noninvasive in vivo positron emission tomography imaging. Clin Cancer Res. 2005;11:7749-7756.

29. Cao F, Lin S, Xie X, et al. In vivo visualization of embryonic stem cell survival, proliferation, and migration after cardiac delivery. Circulation. 2006;113:10051014.

30. Thomis D, Marktel S, Bonini C, et al. A Fas-based suicide switch in human T cells for the treatment of graft-versus-host disease. Blood. 2001;97:1249-1257.

31. Riddell S, Elliott M, Lewinsohn D, et al. T-cell mediated rejection of genemodified HIV-specific cytotoxic T lymphocytes in HIV-infected patients. Nat Med. 1996;2:216-223.

32. Wang L, Munch-Petersen B, Herrstrom Sjoberg A, et al. Human thymidine kinase 2: molecular cloning and characterisation of the enzyme activity with antiviral and cytostatic nucleoside substrates. FEBS Lett. 1999;443:170-174.

33. Welin M, Kosinska U, Mikkelsen N, et al. Structures of thymidine kinase 1 of human and mycoplasmic origin. Proc Natl Acad Sci U S A. 2004;101:17970-17975.

34. Che J, Doubrovin M, Serganova I, Ageyeva L, Zanzonico P, Blasberg R. hNISIRES-eGFP dual reporter gene imaging. Mol Imaging. 2005;4:128-136. 